॥ This article has been updated from its originally published version to correct the affiliations. See the corresponding erratum notice, DOI: $10.3171 / 2020.2 . J N S 182416 a$. «

\title{
Incidence, classification, and treatment of angiographically occult intracranial aneurysms found during microsurgical aneurysm clipping of known aneurysms
}

\author{
Jan-Karl Burkhardt, MD, ${ }^{1}$ Michelle H. Chua, BS, ${ }^{2}$ Ethan A. Winkler, MD, PhD, ${ }^{1}$ \\ W. Caleb Rutledge, MD, ${ }^{1}$ and Michael T. Lawton, MD² \\ 'Department of Neurological Surgery, University of California, San Francisco, California; and 2Department of Neurological \\ Surgery, Barrow Neurological Institute, Phoenix, Arizona
}

\begin{abstract}
OBJECTIVE During the microsurgical clipping of known aneurysms, angiographically occult (AO) aneurysms are sometimes found and treated simultaneously to prevent their growth and protect the patient from future rupture or reoperation. The authors analyzed the incidence, treatment, and outcomes associated with $\mathrm{AO}$ aneurysms to determine whether limited surgical exploration around the known aneurysm was safe and justified given the known limitations of diagnostic angiography.
\end{abstract}

METHODS An AO aneurysm was defined as a saccular aneurysm detected using the operative microscope during dissection of a known aneurysm, and not detected on preoperative catheter angiography. A prospective database was retrospectively reviewed to identify patients with $\mathrm{AO}$ aneurysms treated microsurgically over a 20 -year period.

RESULTS One hundred fifteen AO aneurysms (4.0\%) were identified during 2867 distinct craniotomies for aneurysm clipping. The most common locations for AO aneurysms were the middle cerebral artery ( 60 aneurysms, $54.1 \%$ ) and the anterior cerebral artery (20 aneurysms, 18.0\%). Fifty-six AO aneurysms (50.5\%) were located on the same artery as the known saccular aneurysm. Most AO aneurysms (95.5\%) were clipped and there was no attributed morbidity. The most common causes of failed angiographic detection were superimposition of a large aneurysm (type 1,30.6\%), a small aneurysm (type 2, 18.9\%), or an adjacent normal artery (type 3,36.9\%). Multivariate analysis identified multiple known aneurysms (odds ratio [OR] 3.45, 95\% confidence interval [Cl] 2.16-5.49, $p<0.0001$ ) and young age (OR $0.981,95 \% \mathrm{Cl}$ $0.965-0.997, p=0.0226$ ) as independent predictors of AO aneurysms.

CONCLUSIONS Meticulous inspection of common aneurysm sites within the surgical field will identify AO aneurysms during microsurgical dissection of another known aneurysm. Simultaneous identification and treatment of these additional undiagnosed aneurysms can spare patients later rupture or reoperation, particularly in those with multiple known aneurysms and a history of subarachnoid hemorrhage. Limited microsurgical exploration around a known aneurysm can be performed safely without additional morbidity.

https://thejns.org/doi/abs/10.3171/2018.11.JNS182416

KEYWORDS microsurgical aneurysm clip occlusion; catheter angiography; angiographically occult aneurysm; vascular disorders

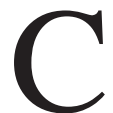
EREBRAL catheter angiography is regarded as the gold standard for detecting ruptured and unruptured intracranial aneurysms. ${ }^{13-16}$ However, tiny aneurysms may be missed even with the best imaging technology and techniques due to small size, human error, and technical inaccuracies, including inadequate imaging projections, the superimposition of other aneurysms or normal vessels, and clip or coil artifact from previously treated aneurysms. Studies in Japanese cohorts have reported the incidence of these angiographically occult (AO) aneurysms to be $3.7 \%-4.9 \%$, most of which were microaneurysms less than $2 \mathrm{~mm}$ in diameter. ${ }^{6,9}$ During the mi-

ABBREVIATIONS $\mathrm{ACA}=$ anterior cerebral artery; $\mathrm{AChA}=$ anterior choroidal artery; $\mathrm{ACOA}=$ anterior communicating artery; $\mathrm{AO}=$ angiographically occult; $\mathrm{BA}=$ basilar apex; CTA = CT angiography; DSA = digital subtraction angiography; ICA = internal carotid artery; ISUIA = International Study of Unruptured Intracranial Aneurysms; MCA = middle cerebral artery; $\mathrm{PCA}=$ posterior cerebral artery; $\mathrm{PCOA}=$ posterior communicating artery; $\mathrm{SAH}=$ subarachnoid hemorrhage.

SUBMITTED August 20, 2018. ACCEPTED November 21, 2018.

INCLUDE WHEN CITING Published online February 22, 2019; DOI: 10.3171/2018.11.JNS182416. 
crosurgical clipping of known aneurysms, these AO aneurysms are commonly found and treated simultaneously to prevent their growth and protect the patient from future rupture or reoperation.

In patients without a history of aneurysmal subarachnoid hemorrhage (SAH), detection of unruptured small aneurysms is less critical because the rupture risk associated with these aneurysms is low. However, accurate diagnosis of these aneurysms might affect the duration and frequency of follow-up imaging surveillance. In patients with a history of $\mathrm{SAH}$, angiographic detection failure may have serious consequences. In the International Study of Unruptured Intracranial Aneurysms (ISUIA), risk of rupture of additional unruptured aneurysms after SAH (group 2) was found to be significantly higher compared to the risk of rupture of unruptured aneurysms in patients without prior SAH (group 1). Therefore, the identification of AO aneurysms is important in reducing these patients' risk of a second SAH and might justify limited surgical exploration in the regions adjacent to a known aneurysm being treated microsurgically. We reviewed an extensive series of aneurysms treated microsurgically to determine the incidence, treatment, and outcomes associated with $\mathrm{AO}$ aneurysms found during surgery for other known aneurysms. We aimed to determine whether limited surgical exploration around the known aneurysm was safe and justified in light of the known limitations of diagnostic angiography.

\section{Methods \\ Inclusion Criteria}

This study was approved by the IRB and performed in compliance with Health Insurance Portability and Accountability Act regulations. Patient consent was not obtained for this study. A prospectively maintained database was reviewed for all ruptured and unruptured aneurysms treated microsurgically by 1 surgeon (senior author M.T.L.) from 1 institution between July 1997 and September 2016. From the group of patients with multiple treated aneurysms, patients with $\mathrm{AO}$ aneurysms treated simultaneously during craniotomy for another known aneurysm were identified based on retrospective reviews of operative reports and preoperative angiography. Specifically, an AO aneurysm was defined as a saccular aneurysm detected using the operative microscope during microsurgical dissection to or around the other known aneurysm, and not detected on preoperative catheter angiography, based on retrospective review of the radiologists' reports. An AO aneurysm had to have a neck and dome that was separate from the other known aneurysm, which thereby eliminated blebs or multiple lobes on the known aneurysm. Patients without preoperative catheter angiographic imaging were excluded from the analysis. Clinical data, including age, sex, presentation, and surgical approach, were collected for all patients. Radiological data, including aneurysm location and morphology, were collected for all aneurysms. Adverse outcome was defined as any neurological changes in the brain supplied by the $\mathrm{AO}$ aneurysm's vascular territory or radiological evidence of infarct or vessel occlusion in the $\mathrm{AO}$ aneurysm's vascular territory.

\section{Microsurgical Dissection}

The extent of microsurgical dissection depended on the location of the known target aneurysm. For the standard lateral approaches (pterional or orbitozygomatic craniotomies), the sylvian fissure was split routinely to provide easy exploration of the supraclinoid internal carotid artery (ICA), including the posterior communicating artery (PCoA), anterior choroidal artery (AChA), and ICA terminus. Fenestration of the lamina terminalis was frequently performed to release CSF and relax the brain, especially in patients with ruptured aneurysms, which allowed inspection of the $\mathrm{A}_{1}$ anterior cerebral artery (ACA) and anterior communicating artery (ACoA) complex. Fenestration of Liliequist's membrane was also frequently performed for CSF release and brain relaxation, again in patients with $\mathrm{SAH}$, facilitating inspection of the basilar quadrifurcation. ${ }^{18}$ Primary microdissection focused on the exposure of the known target aneurysm, and common aneurysm sites within or adjacent to these areas were carefully examined. With other craniotomies, such as the anterior interhemispheric, far lateral, and suboccipital approaches, exploration was limited to the arteries in the dissection pathway to the known aneurysm. Limited exploration was defined as the complete exploration of all arterial segments leading to and adjacent to the known aneurysm, and the extent of exploration was individualized based on anatomy and condition of the brain.

\section{Statistical Analysis}

Statistical analysis was performed using $\mathrm{R}$ (version 3.1.1; http://www.r-project.org). Continuous variables are presented as means with standard deviations and/or ranges when appropriate. In univariable analysis, comparisons between groups were performed using Fisher's exact test for categorical variables and the Wilcoxon signed-rank test for numerical variables. Statistical significance was defined as $p<0.05$.

\section{Results}

\section{Incidence, Location, and Treatment of AO Aneurysms}

$\mathrm{AO}$ aneurysms were identified in 115 patients (4.0\%) during 2867 craniotomies performed for aneurysm treatment. Of the total number of craniotomies, 2770 were performed for saccular aneurysms only, 59 craniotomies were performed for dolichoectatic aneurysms only, and 38 craniotomies were performed for dissecting aneurysms or pseudoaneurysms only. AO aneurysms were identified in 100 (3.6\%) of 2770 craniotomies in patients with known saccular aneurysms, 3 (5.1\%) of 59 craniotomies in patients with known dolichoectatic aneurysms, and 1 (2.6\%) of 38 craniotomies in patients with known dissecting aneurysms or pseudoaneurysms. The incidence of AO aneurysms was higher in patients treated without preoperative catheter angiography (37 of 132 [28\%]) versus those treated with preoperative catheter angiography (115 of 2867 [4.0\%]), reflecting the decreased sensitivity of CT angiography (CTA). These 132 patients without preoperative catheter angiography were excluded from our analysis.

The most common locations for $\mathrm{AO}$ aneurysms in patients with saccular target aneurysms were the middle ce- 
TABLE 1. Characteristics of $A O$ aneurysms

\begin{tabular}{|c|c|c|}
\hline Characteristic & $\begin{array}{l}\text { w/ Known } \\
\text { Saccular } \\
\text { Aneurysms } \\
(n=111)\end{array}$ & $\begin{array}{c}\text { w/ Known Dolichoectatic } \\
\text { Aneurysm or } \\
\text { Pseudoaneurysm } \\
(n=4)\end{array}$ \\
\hline \multicolumn{3}{|l|}{ Location } \\
\hline ACA/ACoA & $20(18.0)$ & $0(0)$ \\
\hline $\mathrm{AChA}$ & $11(9.9)$ & $0(0)$ \\
\hline BA & $5(4.5)$ & $0(0)$ \\
\hline ICA bifurcation & $3(2.7)$ & $0(0)$ \\
\hline $\mathrm{MCA}$ & $60(54.1)$ & $3(75)$ \\
\hline OphA & $4(3.6)$ & $0(0)$ \\
\hline PCA & $1(0.9)$ & $0(0)$ \\
\hline PCoA & $6(5.4)$ & $0(0)$ \\
\hline Supraclinoid ICA & $1(0.9)$ & $1(25)$ \\
\hline $\begin{array}{l}\text { Same vessel or segment } \\
\text { as known aneurysm }\end{array}$ & $56(50.5)$ & $1(25)$ \\
\hline \multicolumn{3}{|l|}{ Morphology } \\
\hline Thin-walled & $29(26.1)$ & $1(25)$ \\
\hline Dysplastic & $3(2.7)$ & $1(25)$ \\
\hline \multicolumn{3}{|l|}{ Treatment } \\
\hline $\begin{array}{l}\text { Microsurgical clipping } \\
\text { w/ temporary clip }\end{array}$ & $27(24.3)$ & $2(50)$ \\
\hline $\begin{array}{l}\text { Microsurgical clipping } \\
\text { w/o temporary clip }\end{array}$ & 79 (71.2) & $2(50)$ \\
\hline Wrapping & $5(4.5)$ & $0(0)$ \\
\hline
\end{tabular}

OphA = ophthalmic artery.

All data given as number (\%).

rebral artery (MCA; $60 \mathrm{AO}$ aneurysms, 54.1\%), ACoA (20 $\mathrm{AO}$ aneurysms, $18.0 \%)$, AChA (11 AO aneurysms, 9.9\%), and PCoA (6 AO aneurysms, 5.4\%; Table 1). Fifty-six AO aneurysms $(50.5 \%)$ were located on the same artery as the known saccular aneurysm and were found during dissection of the target aneurysm, while $55 \mathrm{AO}$ aneurysms (49.5\%) required limited exploration to find the $\mathrm{AO}$ aneurysm. Eleven patients had $2 \mathrm{AO}$ aneurysms noted at the time of craniotomy; in 7 of those patients, the $\mathrm{AO}$ was in the same vessel segment as the target aneurysm (63\%).

All AO aneurysms in patients with known dolichoectatic aneurysms were found on the MCA. Only 1 AO aneurysm (33.3\%) was located in the same vessel or segment as a known dolichoectatic aneurysm. AO aneurysms were noted to be thin-walled or "blister-like" in 29 patients $(25.2 \%)$

The incidence of $\mathrm{AO}$ aneurysms varied over time as shown in Fig. 1A, with a range of $0.9 \%$ to $8.1 \%$ and no significant trend. The advent of 3D rotational angiography did not reduce the incidence of $\mathrm{AO}$ aneurysms in this study population (Fig. 1B).

Overall, $95.5 \%$ of $\mathrm{AO}$ aneurysms were treated by microsurgical clipping using a $3-\mathrm{mm}$ straight or $2.8-\mathrm{mm}$ curved mini-clip in all cases. Aneurysm size could not be measured preoperatively (according to the definition of an $\mathrm{AO}$ aneurysm), but $\mathrm{AO}$ aneurysm size was inferred to have been smaller than $2 \mathrm{~mm}$ by the aneurysm clip used. Temporary clipping of the parent artery was required for 29 AO aneurysms (25.2\%, Table 1$)$, mainly because these
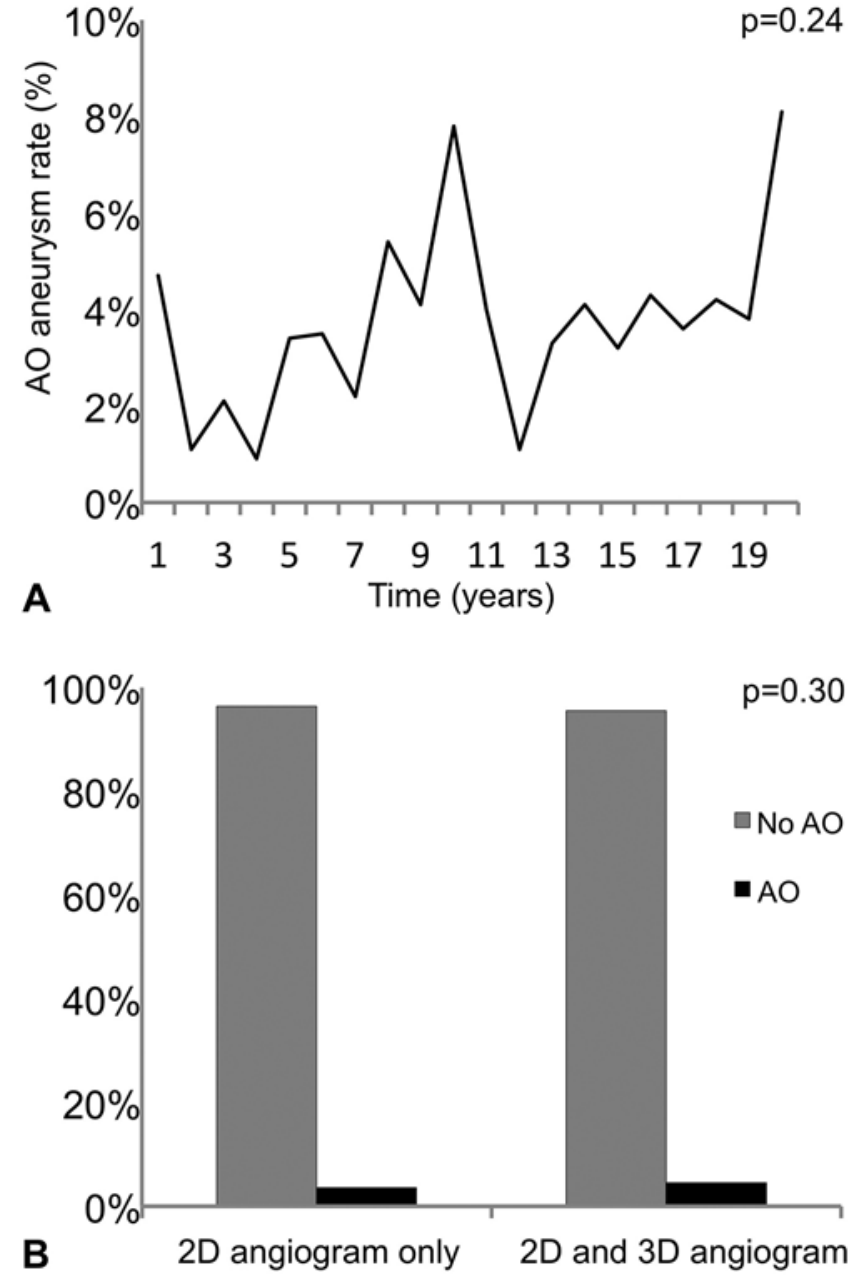

FIG. 1. AO aneurysm rate over time in years $(\mathbf{A})$ and proportion of cases with and without $3 \mathrm{D}$ angiography in patients with and without $\mathrm{AO}$ aneurysms (B).

aneurysms were sessile and small, and softening the aneurysm with a temporary clip facilitated clip application. Use of temporary clipping was not significantly associated with AO aneurysm location ( $\mathrm{p}=0.290$; Table 2). There

TABLE 2. Location of $A O$ aneurysms treated with microsurgical clipping with and without temporary clipping of the parent artery

\begin{tabular}{lcc}
\hline \multirow{2}{*}{ Location } & \multicolumn{2}{c}{ Temporary Clip } \\
\cline { 2 - 3 } ACA/ACoA & Yes $(\mathrm{n}=27)$ & No $(\mathrm{n}=79)$ \\
AChA & $4(14.8)$ & $16(20.3)$ \\
BA & $1(3.7)$ & $10(12.7)$ \\
ICA bifurcation & $1(3.7)$ & $3(3.8)$ \\
MCA & $1(3.7)$ & $2(2.5)$ \\
OphA & $16(59.3)$ & $41(51.9)$ \\
PCA & $0(0)$ & $3(3.8)$ \\
PCoA & $0(0)$ & $1(1.3)$ \\
Supraclinoid ICA & $4(14.8)$ & $2(2.5)$ \\
\hline
\end{tabular}

All data given as number (\%). 
TABLE 3. Classification of $A O$ aneurysms in patients with known saccular aneurysms

\begin{tabular}{lc}
\hline \multicolumn{1}{c}{ Classification } & $\begin{array}{c}\text { AO Aneurysms } \\
(\mathrm{n}=111)\end{array}$ \\
\hline Type 1 (superimposition of larger adjacent aneurysm) & $34(30.6 \%)$ \\
\hline Type 2 (superimposition of small adjacent aneurysm) & $21(18.9 \%)$ \\
\hline $\begin{array}{l}\text { Type 3 (superimposition of vessels or inadequate } \\
\text { projections) }\end{array}$ & $41(36.9 \%)$ \\
\hline Type 4 (concealed by treatment artifact) & $15(13.5 \%)$ \\
\hline
\end{tabular}

were no complications or new neurological deficits associated with treatment of $\mathrm{AO}$ aneurysms.

\section{Causes of Angiographic Detection Failure in Patients With Saccular Aneurysms}

Failure to detect AO aneurysms was categorized into 4 types: 1) superimposition of an adjacent large aneurysm (>5 mm in diameter; type 1,34 AO aneurysms, 30.6\%);2) superimposition of an adjacent small aneurysm $(\leq 5 \mathrm{~mm}$ in diameter; type 2, $21 \mathrm{AO}$ aneurysms, 18.9\%); 3) superimposition of adjacent normal vessels, with inadequate projections or poor filling of the PCoA (type 3, $41 \mathrm{AO}$ aneurysms, 36.9\%); and 4) artifact from prior microsurgical clipping and/or endovascular coiling (type 4,15 AO aneurysms, $13.5 \%$; Table 3). Type 1 aneurysms were most commonly located on the MCA (47.1\%) and supraclinoid ICA (26.5\%). Type 2 and 3 aneurysms were most commonly located in the MCA segment $(71.4 \%$ and $63.4 \%$, respectively; Table 4). In our cohort, large (>5 mm) and small $(\leq 5 \mathrm{~mm})$ MCA aneurysms were identified on preoperative vascular imaging prior to 298 and 334 craniotomies, with type 1 and type 2 AO incidences of 5.7\% (17/298) and $4.8 \%$ (16/334), respectively.

\section{Predictors of AO Aneurysms in Patients With Known Saccular Aneurysms}

Multiple known aneurysms ( $\mathrm{p}<0.0001)$, known MCA aneurysm $(p=0.0306)$, and younger age $(p=0.0310)$ were identified as significant predictors of $\mathrm{AO}$ aneurysms in univariable analysis (Table 5). Sex, aneurysmal SAH, known supraclinoid ICA aneurysm, and chronology of surgery were not significantly associated with AO aneurysms. In multivariable analysis, only multiple known an-

TABLE 4. Location of AO aneurysms in patients with known saccular aneurysms

\begin{tabular}{ccccc}
\hline $\begin{array}{c}\text { AO Aneurysm } \\
\text { Type }\end{array}$ & $\begin{array}{c}\text { ACA/ } \\
\text { ACoA }\end{array}$ & $\begin{array}{c}\text { BA/PCA/ } \\
\text { SCA }\end{array}$ & MCA & $\begin{array}{c}\text { Supraclinoid } \\
\text { ICA }^{*}\end{array}$ \\
\hline Type 1 & $5(14.7)$ & $4(11.8)$ & $16(47.1)$ & $9(26.5)$ \\
\hline Type 2 & $4(19)$ & $1(4.8)$ & $15(71.4)$ & $1(4.8)$ \\
\hline Type 3 & $11(26.8)$ & $1(2.4)$ & $26(63.4)$ & $3(7.3)$ \\
\hline Type 4 & $1(6.7)$ & 0 & $10(66.7)$ & $4(26.7)$ \\
\hline
\end{tabular}

SCA = superior cerebellar artery.

All data given as number (\%).

* Including the AChA and PCoA.
TABLE 5. Predictors of $A O$ aneurysms in patients with known saccular aneurysms

\begin{tabular}{lccc}
\hline \multirow{2}{*}{ Predictor } & \multicolumn{2}{c}{ AO Aneurysm } & \\
\cline { 2 - 3 } & Yes $(\mathrm{n}=100)$ & No $(\mathrm{n}=2670)$ & p Value \\
\hline Mean age \pm SD (yrs) & $53.0 \pm 12.0$ & $56.0 \pm 14.0$ & 0.0310 \\
\hline Sex & & & 0.897 \\
$\quad$ Male & $28(28.0)$ & $718(26.9)$ & \\
$\quad$ Female & $72(72.0)$ & $1952(73.1)$ & \\
\hline Aneurysmal SAH & $53(53.0)$ & $1235(46.3)$ & 0.220 \\
\hline Multiple known aneurysms & $42(42.0)$ & $533(20.0)$ & $<0.0001$ \\
\hline Known ACA/ACoA aneurysm & $37(37.0)$ & $740(27.7)$ & 0.0554 \\
\hline Known MCA aneurysm & $39(39.0)$ & $761(28.5)$ & 0.0306 \\
\hline Known supraclinoid ICA & $36(36.0)$ & $852(31.9)$ & 0.453 \\
$\quad$ aneurysm & & & \\
\hline Date of surgery & & & 0.205 \\
$\quad 7 / 1997-6 / 2002$ & $13(13.0)$ & $501(18.8)$ & \\
$7 / 2002-6 / 2007$ & $32(32.0)$ & $729(27.3)$ & \\
$7 / 2007-6 / 2012$ & $28(28.0)$ & $871(32.6)$ & \\
$7 / 2012-9 / 2016$ & $27(27.0)$ & $569(21.3)$ & \\
\hline
\end{tabular}

All data given as number (\%) unless otherwise indicated.

eurysms (odds ratio [OR] 3.45, 95\% confidence interval [CI $2.16-5.49, \mathrm{p}<0.0001)$ and young age (OR $0.981,95 \%$ CI $0.965-0.997, \mathrm{p}=0.0226$ ) were independent predictors of $\mathrm{AO}$ aneurysms.

\section{Case Presentations}

Case 1: Type 1 AO Aneurysm. This 44-year-old woman presented with rupture of a large, superiorly projecting right $\mathrm{P}_{1}$ posterior cerebral artery (PCA) aneurysm (Fig. $2 \mathrm{~A}-\mathrm{C})$. The aneurysm was microsurgically clipped via an orbitozygomatic-pterional craniotomy. During microdissection, a small basilar apex (BA) aneurysm was identified and clipped (Fig. 2D). Postoperative angiography confirmed clipping of both aneurysms (Fig. 2E and F). Failure to detect the BA aneurysm on preoperative angiography was most likely due to its small size and superimposition of the large PCA aneurysm over the basilar quadrifurcation.

Case 2: Type 2 AO Aneurysm. This 45-year-old man with a history of amphetamine abuse presented with sudden headache and confusion. A small, ruptured ACoA aneurysm was found on catheter angiography (Fig. 3A-C). This was surgically clipped through a left pterional craniotomy (Fig. 3D and E). An additional anteriorly and inferiorly projecting unruptured aneurysm with a wide neck was found during dissection of the ACoA complex and clipped with a slightly curved mini-clip (Fig. 3F-H). Postoperative angiography confirmed complete occlusion of both aneurysms (Fig. 3I and J) and the patient recovered without deficits. The occult ACoA aneurysm was not visualized on preoperative angiography, most likely due to its small size and superimposition of the small, ruptured ACoA aneurysm nearby.

Case 3: Type 3 AO Aneurysm. This 53-year-old woman presented with a ruptured ICA pseudoaneurysm. Initial 

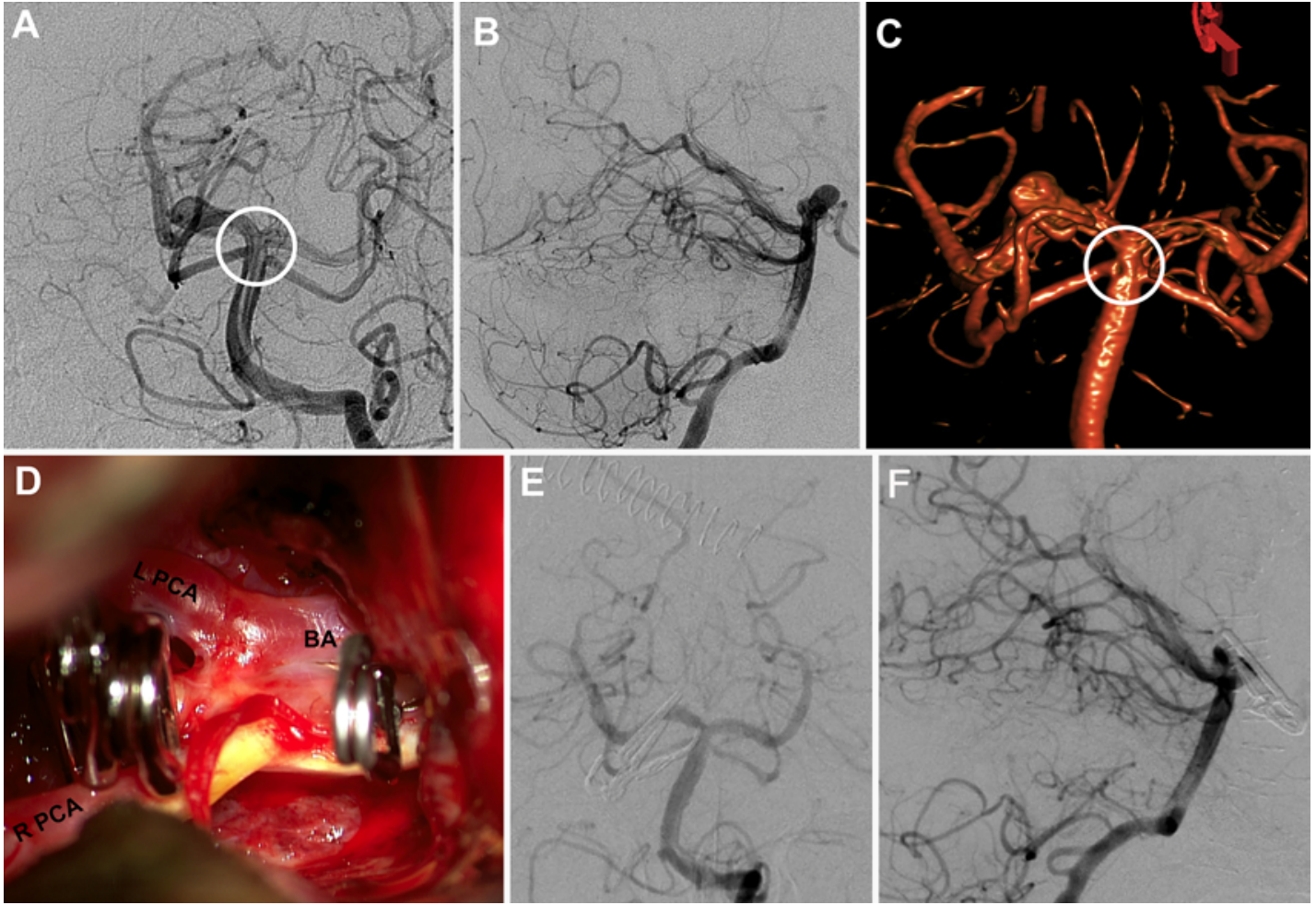

FIG. 2. Case 1. A 44-year-old woman with a right PCA ( $P_{1}$ segment) aneurysm clipped via an orbitozygomatic transsylvian approach. During surgery an additional small BA aneurysm was found and clipped (D), which was not observed on preoperative angiography (A-C; circles indicate region of additional aneurysm found during surgery). Postoperative angiography confirmed clipping of the 2 aneurysms (E and F).

CTA revealed only a small aneurysm, which had increased significantly in size at the time of catheter angiography (Fig. 4A-C). Microsurgical clipping was successful and a bypass procedure was not required (Fig. 4D). A small MCA bifurcation aneurysm was discovered when splitting the sylvian fissure and clipped with a slightly curved mini-clip with temporary $\mathrm{M}_{1}$ MCA clipping (Fig. 4E-G). Postoperative CTA and catheter angiography confirmed complete occlusion of both aneurysms (Fig. 4H), but the ICA pseudoaneurysm recurred 1 week later. This was reclipped and the pseudoaneurysm remained occluded thereafter. The patient recovered well and remained neurologically intact. In our cohort, $50.4 \%$ of $\mathrm{AO}$ aneurysms were located on an artery different from the known aneurysm and discovered on approach to the target aneurysm. In this case, the occult aneurysm was not seen on preoperative angiography due to its small size, with possible superimposition of branching vessels of the MCA bifurcation.

\section{Discussion}

In this report, we define the incidence, location, treatment, outcomes, and predictors of AO aneurysms. We also categorized the likely causes of angiographic detection failure into 4 types. With an overall incidence of $4.0 \%$, $\mathrm{AO}$ aneurysms are not uncommon findings at surgery for another known aneurysm. This incidence was comparable to two previously reported case series. ${ }^{6,9}$ We included only patients with $\mathrm{AO}$ aneurysms with preoperative digital subtraction angiography (DSA); had we included patients with $\mathrm{AO}$ aneurysms without preoperative DSA, the $28 \%$ incidence in this group would have increased the overall incidence of $\mathrm{AO}$ aneurysms. AO aneurysms were located most frequently on the MCA and ACoA, and furthermore, there was a significantly higher incidence of AO aneurysms in the MCA and ACoA segments in patients with known MCA and ACoA aneurysms $(5.2 \%$ vs $1.3 \%$ for MCA aneurysms [p $<0.0001]$ and $2.6 \%$ vs $0.6 \%$ for ACoA aneurysms [p $<0.0001]$ in patients with and without known aneurysms there, respectively). This finding implicates aneurysm superimposition as a significant cause of failed angiographic detection.

Villablanca and coworkers also attributed angiographic detection failure to superimposition of adjacent normal vessels at the MCA bifurcation and ACoA complex, due to complex branching patterns at these sites. These authors also implicated a failure to obtain adequate imaging projections at locations such as the BA, and poor filling of the PCoA in the setting of balanced anterior and posterior circulation flows (type 3$).{ }^{17}$ In our cohort, these technical inadequacies were the most common causes of angiographic detection failure (36.9\% of AO aneurysms), more than large aneurysm superimposition (type 1, 30.6\%) and small aneurysm superimposition (type 2, 18.9\%).

Surprisingly, we found no difference in detection of $\mathrm{AO}$ aneurysms over the 20-year time period of the study, suggesting that improvements in imaging technology such as 

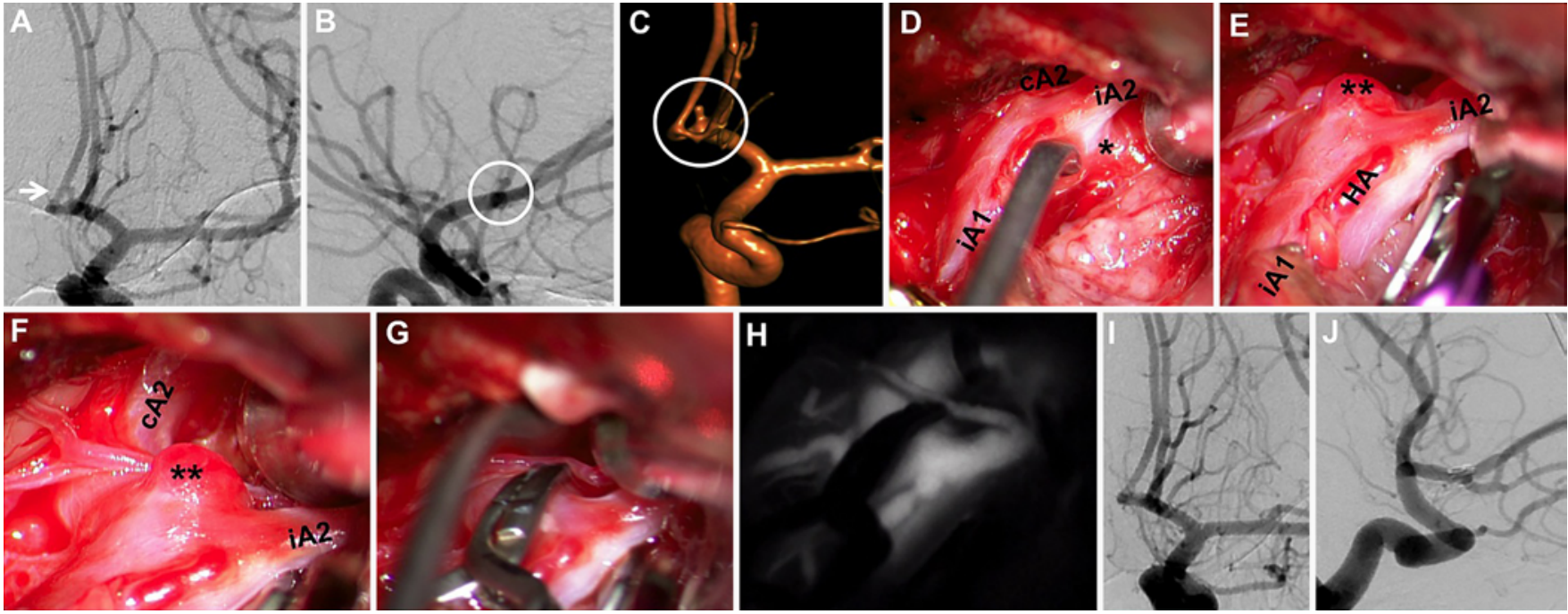

FIG. 3. Case 2. A 45-year-old man with a small, ruptured $A C o A$ aneurysm (arrow, A) that was found on catheter angiography $(A-C)$, which was surgically clipped through a left pterional craniotomy ( $D$ and $E)$. An additional anteriorly and inferiorly projecting unruptured $\mathrm{ACOA}$ aneurysm was found and clipped $(\mathrm{F}-\mathrm{H})$, which was not seen on preoperative angiography (B and $\mathrm{C}$, circles indicate region of additional aneurysm found during surgery). Postoperative angiography confirmed complete occlusion of both aneurysms $(\mathrm{I}$ and $\mathrm{J})$. iA1 = ipsilateral $\mathrm{A}_{1} \mathrm{ACA} ; \mathrm{i} 2 \mathrm{2}=$ ipsilateral $\mathrm{A}_{2} \mathrm{ACA} ; \mathrm{HA}=$ recurrent artery of Heubner; $\mathrm{cA} 2=$ contralateral $\mathrm{A}_{2}$ ACA. *known aneurysm; **occult aneurysm.

3D rotational angiography have not lowered the incidence of AO aneurysms. Previously published studies showed a higher sensitivity and specificity of 3D rotational angiography compared to standard biplane DSA to detect aneurysms. ${ }^{10,20}$ Wong et al. demonstrated that although 2D DSA had a false-negative aneurysm detection rate of $6.8 \%$ compared to 3D rotational angiography in CT-negative patients, the aneurysm size in the detected aneurysms was comparable between $2 \mathrm{D}$ and $3 \mathrm{D}$ angiography. ${ }^{20}$ Kucukay et al. pointed out that aneurysms missed by $2 \mathrm{D}$ angiography had a mean size of $2.79 \pm 0.74 \mathrm{~mm},{ }^{10}$ which is above the $\mathrm{AO}$ aneurysm size range observed during surgery. This might explain why there was no difference in the AO aneurysm incidences in patients with and without 3D rotational angiography, because some of these $\mathrm{AO}$ aneurysms are too small even for current 3D rotational angiography. Because objective aneurysm size measurements are not possible preoperatively (by definition), we used aneurysm clip size to estimate aneurysm size. In our cohort, all AO aneurysms were treated with a mini-clip less than or equal to $3 \mathrm{~mm}$, which infers an $\mathrm{AO}$ aneurysm size of approximately $2 \mathrm{~mm}$. It is worth remembering that contrast-based DSA only shows contrast filling within the aneurysm without imaging the aneurysm wall, and with such small aneurysms, magnified inspection of wall thinning and aneurysmal expansion under the microscope at surgery is probably superior to luminal filling with contrast.

All AO aneurysms in our cohort were safely treated, mostly by microsurgical clipping. Our working hypothesis was that limited microsurgical exploration around a known aneurysm could be performed safely without causing additional morbidity, and the results of this study support this hypothesis. The incidence of AO aneurysms and the safety of limited surgical exploration around known aneurysms argue for vigilance during subarachnoid dissection. High- risk patients and high-risk locations should be actively examined during microdissection and treated if found. We are not advocating for exhaustive explorations or risky microdissection, but simply for increased inspection of aneurysm sites that are already within the surgical corridor. This practice is particularly relevant in patients presenting with SAH and multiple aneurysms, with inspection of the ACA and MCA segments in particular. Pterional or orbitozygomatic craniotomies with transsylvian dissection that includes double fenestration of the lamina terminalis and membrane of Liliequist for CSF drainage and prevention of hydrocephalus provide easy opportunities to inspect multiple sites for AO aneurysms without much extra microdissection. ${ }^{19}$ With these steps as our routine, we were able to screen the MCA bifurcation, supraclinoid ICA, ACoA, and less commonly the BA. However, we caution against overdissection in patients with extensive SAH and swollen brains.

AO aneurysms likely represent newly formed aneurysms that might enlarge over time if left untreated. However, the natural history of AO aneurysms is unknown and difficult to study. In addition, $25.2 \%$ of AO aneurysms were noted to be thin-walled or "blister-like," a morphological observation that has been associated with a high risk of aneurysm rupture..$^{2}$ Associated aneurysms in patients with another ruptured aneurysm are especially dangerous, because unruptured aneurysms in these patients have a higher risk of rupture compared to unruptured small aneurysms in patients without prior SAH. Treatment of even small unruptured aneurysms is recommended in these ISUIA group 2 patients. ${ }^{7}$ Of note, the presence of multiple aneurysms has been identified as a risk factor for de novo aneurysm formation in prior reports. ${ }^{1-3,18}$ The presence of multiple aneurysms was a strong and independent predictor of AO aneurysms in our cohort (42.0\% vs $20.0 \%$, OR 

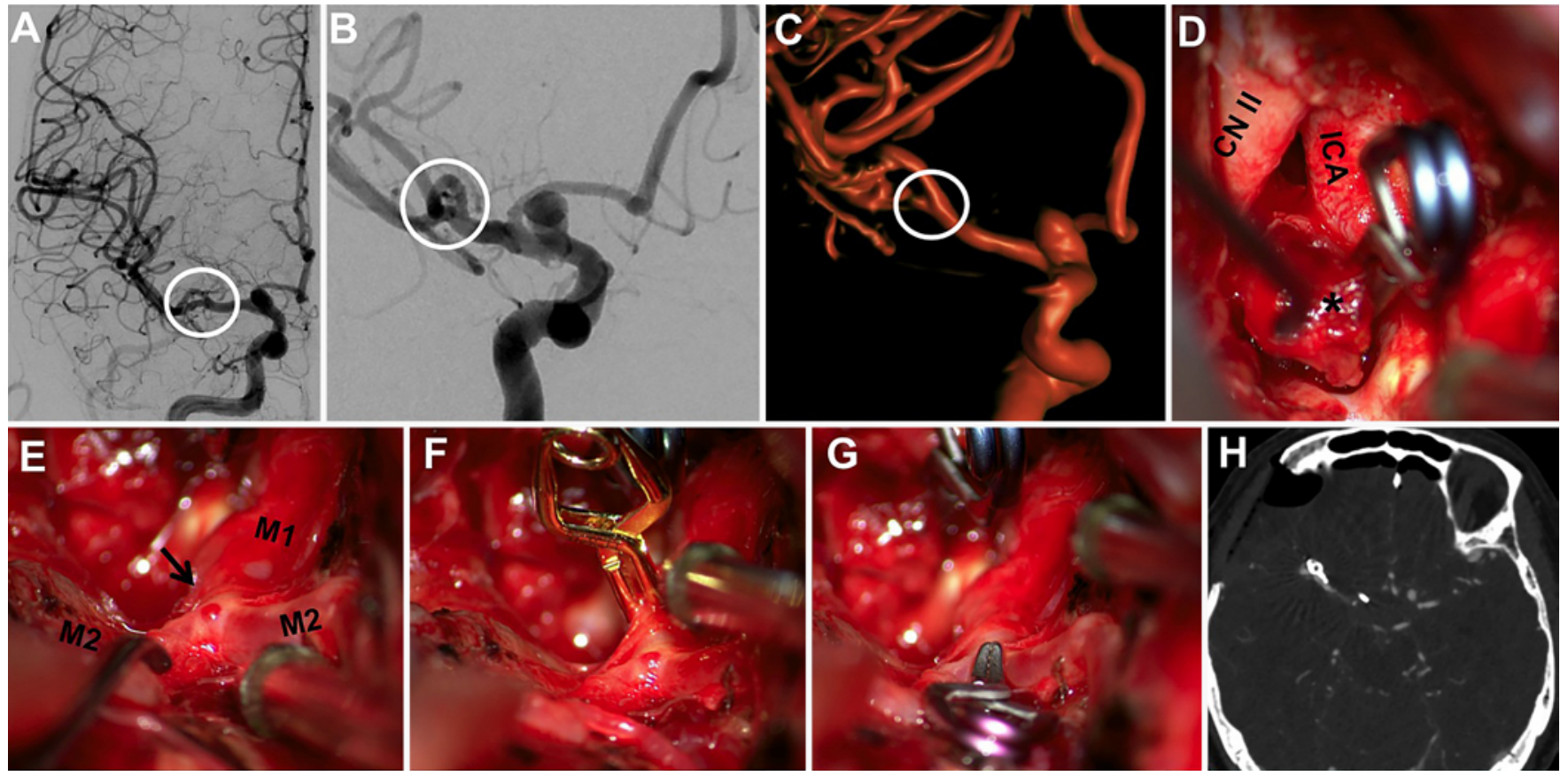

FIG. 4. Case 3. A 53-year-old woman underwent clip placement for a right ICA pseudoaneurysm (asterisk, D). Preoperative catheter angiography (A-C, circles indicate region of additional aneurysm found during surgery) was not able to show an additional AO MCA aneurysm (arrow) found during surgery $(\mathbf{E})$, which was clipped with temporary occlusion of the $\mathrm{M}_{1}$ segment $(\mathbf{F}$ and $\mathbf{G})$. Postoperative CTA shows the clipped aneurysms $(\mathrm{H})$. CN II = cranial nerve II.

$3.45, \mathrm{p}<0.0001)$, suggesting that certain individuals may be predisposed by genetic, hemodynamic, and other risk factors to a dynamic process of aneurysm formation. ${ }^{4}$

In addition to meticulous microsurgical inspection during clipping of known aneurysms, we also advocate longterm angiographic follow-up 5 years after both endovascular and microsurgical therapy in patients with multiple aneurysms. This report has focused on AO aneurysms associated with a known aneurysm, but similar aneurysms not associated with a known aneurysm may account for some cases of nonperimesencephalic angiography-negative $\mathrm{SAH}$, which has an estimated incidence of up to $24 \%$ in the literature..$^{5,8,11}$

Limited surgical exploration around the known aneurysm raises some issues regarding informed consent. When an aneurysm is found unexpectedly at surgery, the patient cannot participate in the decision to treat or not to treat. Therefore, it is important to mention the possibility of an AO aneurysm beforehand with the patient. In our practice, most patients willingly consent to treating these additional AO aneurysms, and are quite relieved to learn postoperatively that they were treated.

This study is limited by its retrospective design, but the data summarize a long, consecutive experience of a single neurosurgeon with a high-volume practice and a standardized approach to microsurgery for intracranial aneurysms. The results from this single-surgeon experience may not be generalizable to other practices. Our reported incidence of $\mathrm{AO}$ aneurysms underestimates their true incidence because exploration was limited to areas within the dissection pathway to target aneurysms, intraoperative inspection was limited by the surgical exposure, and tiny aneu- rysms can easily be hidden. The retrospective nature of this study precluded detailed quantification of the extent of exploratory dissection. The measured incidence of $\mathrm{AO}$ aneurysms was influenced by this variable extent of exploration. Adverse outcomes associated with the treatment of $\mathrm{AO}$ aneurysms might be difficult to differentiate from the overall outcomes associated with the target aneurysm when the two aneurysms were in close proximity. The problem of failed angiographic detection of aneurysms with catheter angiography represents a shortcoming of the diagnostic study with the highest imaging resolution. Our reported incidence of AO aneurysms also underestimates the magnitude of the clinical problem because CTA is being used increasingly as a less invasive alternative to catheter angiography. The aneurysm detection problem is even worse with CTA and MR angiography because of their lower imaging resolution. We excluded such patients from our analysis, and the inclusion of 37 patients with $\mathrm{AO}$ aneurysms after CTA would have increased their overall incidence in our report. Therefore, the importance of limited microsurgical exploration around a known aneurysm to find AO aneurysms will grow as the use of CTA and MR angiography increases or supplants invasive catheter angiography.

\section{Conclusions}

This analysis of $\mathrm{AO}$ aneurysms found during microsurgical dissection of another known aneurysm demonstrates the importance of meticulous inspection of common aneurysm sites within the surgical field. Simultaneous identification and treatment of these additional undiagnosed 
aneurysms can spare patients later rupture or reoperation, particularly in patients with multiple known aneurysms and a history of SAH. Although extra inspection might require more subarachnoid dissection, limited microsurgical exploration around a known aneurysm can be performed safely without causing additional morbidity. However, our results are not generalizable because they represent a single-surgeon experience.

\section{References}

1. Brown MA, Parish J, Guandique CF, Payner TD, Horner T, Leipzig T, et al: A long-term study of durability and risk factors for aneurysm recurrence after microsurgical clip ligation. J Neurosurg 126:819-824, 2017

2. Bruneau M, Rynkowski M, Smida-Rynkowska K, Brotchi J, De Witte O, Lubicz B: Long-term follow-up survey reveals a high yield, up to $30 \%$ of patients presenting newly detected aneurysms more than 10 years after ruptured intracranial aneurysms clipping. Neurosurg Rev 34:485-496, 2011

3. David CA, Vishteh AG, Spetzler RF, Lemole M, Lawton MT, Partovi S: Late angiographic follow-up review of surgically treated aneurysms. J Neurosurg 91:396-401, 1999

4. Etminan N, Rinkel GJ: Unruptured intracranial aneurysms: development, rupture and preventive management. Nat Rev Neurol 12:699-713, 2016

5. Fontanella M, Rainero I, Panciani PP, Schatlo B, Benevello C, Garbossa D, et al: Subarachnoid hemorrhage and negative angiography: clinical course and long-term follow-up. Neurosurg Rev 34:477-484, 2011

6. Inamasu J, Suga S, Horiguchi T, Akaji K, Mayanagi K, Kawase T: Cerebral microaneurysms found incidentally during aneurysm surgery. Neurol Res 23:304-308, 2001

7. International Study of Unruptured Intracranial Aneurysms Investigators: Unruptured intracranial aneurysms-risk of rupture and risks of surgical intervention. N Engl J Med 339:1725-1733, 1998

8. Jung JY, Kim YB, Lee JW, Huh SK, Lee KC: Spontaneous subarachnoid haemorrhage with negative initial angiography: a review of 143 cases. J Clin Neurosci 13:1011-1017, 2006

9. Karasawa H, Matsumoto H, Naito H, Sugiyama K, Ueno J, Kin H: Angiographically unrecognized microaneurysms: intraoperative observation and operative technique. Acta Neurochir (Wien) 139:416-420, 1997

10. Kucukay F, Okten RS, Tekiner A, Dagli M, Gocek C, Bayar $\mathrm{MA}$, et al: Three-dimensional volume rendering digital subtraction angiography in comparison with two-dimensional digital subtraction angiography and rotational angiography for detecting aneurysms and their morphological properties in patients with subarachnoid hemorrhage. Eur J Radiol 81:2794-2800, 2012

11. Kumar R, Das KK, Sahu RK, Sharma P, Mehrotra A, Srivastava AK, et al: Angio negative spontaneous subarachnoid hemorrhage: Is repeat angiogram required in all cases? Surg Neurol Int 5:125, 2014

12. Meng H, Tutino VM, Xiang J, Siddiqui A: High WSS or low WSS? Complex interactions of hemodynamics with intracranial aneurysm initiation, growth, and rupture: toward a unifying hypothesis. AJNR Am J Neuroradiol 35:1254-1262, 2014

13. Philipp LR, McCracken DJ, McCracken CE, Halani SH, Lo- vasik BP, Salehani AA, et al: Comparison between CTA and digital subtraction angiography in the diagnosis of ruptured aneurysms. Neurosurgery 80:769-777, 2017

14. Pradilla G, Wicks RT, Hadelsberg U, Gailloud P, Coon AL, Huang J, et al: Accuracy of computed tomography angiography in the diagnosis of intracranial aneurysms. World Neurosurg 80:845-852, 2013

15. Romijn M, Gratama van Andel HA, van Walderveen MA, Sprengers ME, van Rijn JC, van Rooij WJ, et al: Diagnostic accuracy of CT angiography with matched mask bone elimination for detection of intracranial aneurysms: comparison with digital subtraction angiography and 3D rotational angiography. AJNR Am J Neuroradiol 29:134-139, 2008

16. van Asch CJ, Velthuis BK, Rinkel GJ, Algra A, de Kort GA, Witkamp TD, et al: Diagnostic yield and accuracy of CT angiography, MR angiography, and digital subtraction angiography for detection of macrovascular causes of intracerebral haemorrhage: prospective, multicentre cohort study. BMJ 351:h5762, 2015

17. Villablanca JP, Jahan R, Hooshi P, Lim S, Duckwiler G, Patel $A$, et al: Detection and characterization of very small cerebral aneurysms by using 2D and 3D helical CT angiography. AJNR Am J Neuroradiol 23:1187-1198, 2002

18. Wermer MJ, van der Schaaf IC, Velthuis BK, Algra A, Buskens E, Rinkel GJ: Follow-up screening after subarachnoid haemorrhage: frequency and determinants of new aneurysms and enlargement of existing aneurysms. Brain 128:2421-2429, 2005

19. Winkler EA, Burkhardt JK, Rutledge WC, Rick JW, Partow $\mathrm{CP}$, Yue JK, et al: Reduction of shunt dependency rates following aneurysmal subarachnoid hemorrhage by tandem fenestration of the lamina terminalis and membrane of Liliequist during microsurgical aneurysm repair. J Neurosurg 129:1107-1375, 2018

20. Wong SC, Nawawi O, Ramli N, Abd Kadir KA: Benefits of 3 D rotational DSA compared with 2D DSA in the evaluation of intracranial aneurysm. Acad Radiol 19:701-707, 2012

\section{Disclosures}

The authors report no conflict of interest concerning the materials or methods used in this study or the findings specified in this paper.

\section{Author Contributions}

Conception and design: Lawton, Burkhardt. Acquisition of data: Burkhardt, Chua, Winkler, Rutledge. Analysis and interpretation of data: Burkhardt, Chua, Winkler, Rutledge. Drafting the article: Burkhardt, Chua. Critically revising the article: Lawton, Winkler, Rutledge. Reviewed submitted version of manuscript: all authors. Approved the final version of the manuscript on behalf of all authors: Lawton. Statistical analysis: Burkhardt, Chua. Administrative/technical/material support: Lawton. Study supervision: Lawton.

\section{Correspondence}

Michael T. Lawton: Barrow Neurological Institute, Phoenix, AZ. michael.lawton@barrowbrainandspine.com. 